\title{
Assembly of Multicomponent Nano-Bioconjugates Composed of Mesoporous Silica Nanoparticles, Proteins, and Gold Nanoparticles
} \author{
Giulia Rossella Delpiano, ${ }^{\dagger}$ Maria F. Casula, ${ }^{\dagger, \perp}{ }^{\oplus}$ Marco Piludu, ${ }^{\ddagger}{ }^{\ddagger}$ Riccardo Corpino, ${ }^{\S}$ Pier Carlo Ricci, ${ }^{\S} \odot$
} María Vallet-Regí,

${ }^{\dagger}$ Department of Chemical and Geological Sciences, University of Cagliari, CSGI, INSTM and CNBS, Cittadella Universitaria, S.S. 554 bivio Sestu, 09042 Monserrato, CA, Italy

${ }^{\ddagger}$ Department of Biomedical Sciences and ${ }^{\S}$ Department of Physics, University of Cagliari, Cittadella Universitaria, S.S. 554 bivio Sestu, 09042 Monserrato, CA, Italy

"Departamento de Quimica Inorganica y Bioinorganica, Facultad de Farmacia, Universidad Complutense de Madrid, Instituto de Investigacion Sanitaria Hospital 12 de Octubre i+12, and Centro de Investigacion Biomedica en Red de Bioingenieria, Biomateriales y Nanomedicina (CIBER-BBN), Plaza Ramon y Cajal S/N, 28040 Madrid, Spain

Supporting Information

ABSTRACT: The purpose of this work was the assembly of multicomponent nano-bioconjugates based on mesoporous silica nanoparticles (MSNs), proteins (bovine serum albumin, BSA, or lysozyme, LYZ), and gold nanoparticles (GNPs). These nanobioconjugates may find applications in nanomedicine as theranostic devices. Indeed, MSNs can act as drug carriers, proteins stabilize MSNs within the bloodstream, or may have therapeutic or targeting functions. Finally, GNPs can either be used as contrast agents for imaging or for photothermal therapy. Here, amino-functionalized MSNs $\left(\mathrm{MSN}-\mathrm{NH}_{2}\right)$ were synthesized and characterized through various techniques (small angle $\mathrm{X}$-rays scattering TEM, $\mathrm{N}_{2}$ adsorption/desorption isotherms, and thermogravimetric analysis (TGA)). BSA or lysozyme were then

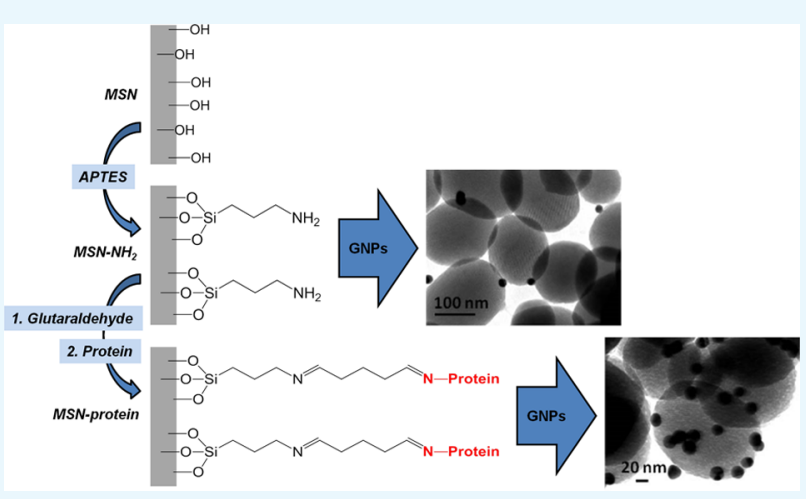
grafted on the external surface of $\mathrm{MSN}-\mathrm{NH}_{2}$ to obtain MSN-BSA and MSN-LYZ bioconjugates, respectively. Protein immobilization on MSNs surface was confirmed by Fourier transform infrared spectroscopy, $\zeta$-potential measurements, and TGA, which also allowed the estimation of protein loading. The MSN-protein samples were then dispersed in a GNP solution to obtain MSN-protein-GNPs nano-bioconjugates. Transmission electron microscopy (TEM) analysis showed the occurrence of GNPs on the MSN-protein surface, whereas almost no GNPs occurred in the protein-free control samples. Fluorescence and Raman spectroscopies suggested that proteins-GNP interactions involve tryptophan residues.

\section{INTRODUCTION}

Nanomedicine is a branch of medicine based on the use of diagnostic and therapeutic nanodevices. ${ }^{1-3}$ Nanodevices take advantage of the specific physicochemical properties of matter at the nanoscale and thus behave differently from their bulk counterparts. ${ }^{4}$ There is a wide range of biomedical nanodevices, and various combinations of them exist. A relevant example is provided by mesoporous silica nanoparticles (MSNs), ${ }^{5}$ which are very promising drug delivery systems. ${ }^{6-9}$ MSNs, besides being highly stable and biocompatible, ${ }^{10}$ combine a high external-surface-to-volume ratio with extended inner surface area and tailored porosity. These features can be exploited for the immobilization and the controlled release of drugs $^{11-18}$ or biological macromolecules. ${ }^{19-22}$ External surface functionalization plays a key role to promote targeting ${ }^{13}$ and to enhance the biocompatibility of MSNs. ${ }^{23,24}$ Indeed, if the external surface of MSNs is functionalized with a charged biopolymer, as for instance hyaluronic acid, a high degree of cell internalization, which is likely mediated by a CD44 receptor in a peculiar kind of cell membranes, can be observed. $^{25,26}$

Several previous studies focused on the interactions between mesoporous silica-based materials and enzymes/proteins. ${ }^{27-29}$ These bioconjugates can be engineered for biocatalytic or biomedical applications depending on the fact that either an enzyme or a therapeutic protein is used. ${ }^{30-32}$ Micrometric mesoporous silica particles, such as SBA-15 (pore size 6-9 $\mathrm{nm})$, can adsorb proteins/enzymes on the internal surface, ${ }^{33,34}$ whereas MSNs of the type MCM-41 (pore size $\approx 2 \mathrm{~nm}$ ) mainly address protein adsorption on the external surface. Coating by specific proteins is used to stabilize nanoparticles in body fluids and thus MSNs can be injected in the

Received: April 30, 2019

Accepted: May 28, 2019

Published: June 25, 2019 
Scheme 1. Assembly of the MSN-Protein-GNP Nano-Bioconjugates ${ }^{a}$

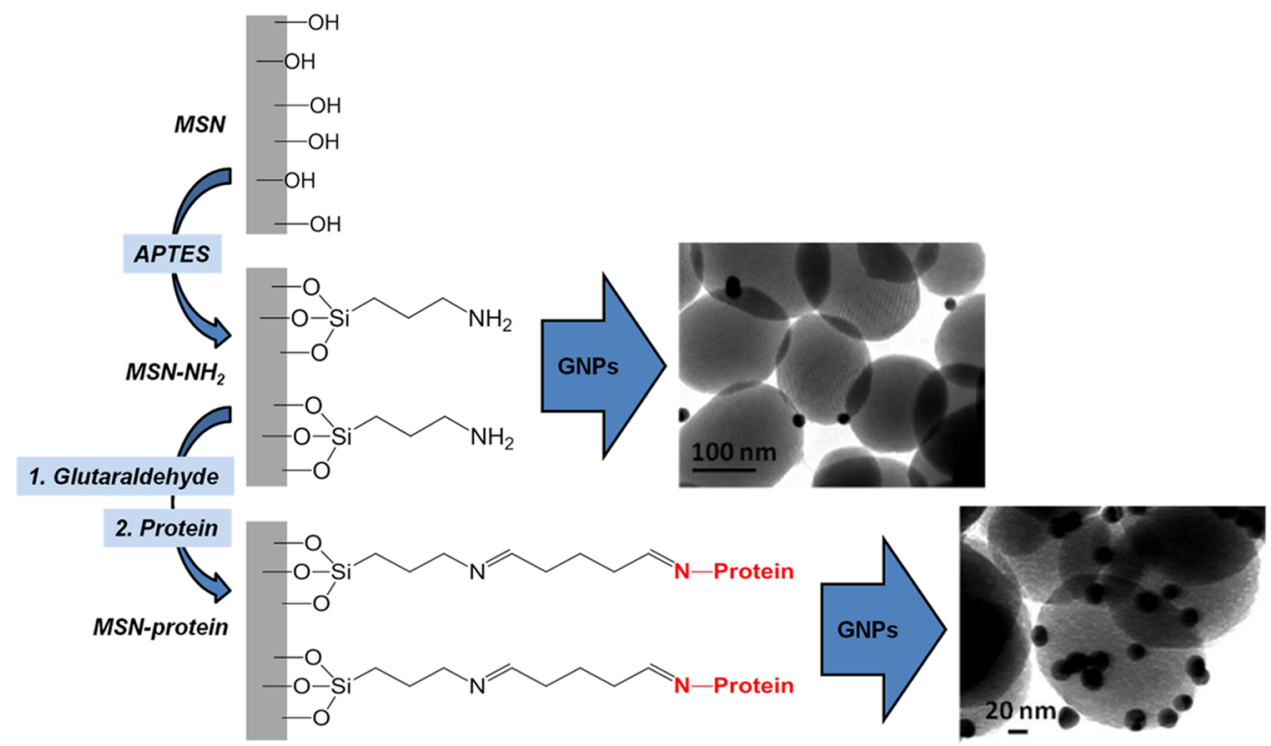

${ }^{a_{T}}$ The MSN surface is functionalized with aminopropyltriethoxysilane (APTES) to obtain MSN- $\mathrm{NH}_{2}$. Proteins (BSA or lysozyme) are grafted, by means of glutaraldehyde, on the external surface of $\mathrm{MSN}-\mathrm{NH}_{2}$ to obtain MSN-protein bioconjugates. The MSN-protein samples are dispersed in a gold nanoparticle (GNP) solution to obtain MSN-protein-GNPs nano-bioconjugates. TEM images show the occurrence of GNPs on the MSN-protein surface, whereas almost no GNPs occur in the protein-free control samples.

bloodstream. ${ }^{35,36}$ To this purpose, blood plasma proteins, such as serum albumins, are the most widely used. ${ }^{37,38}$ Other proteins, such as antibodies, as well as nucleic acids or simple peptides, are able to carry out a targeting function, ${ }^{39,40}$ dragging nanoparticles to target receptors of cells or organs and, therefore, reducing side effects and administration doses. $^{41,42}$ Additionally, plasma proteins are naturally adsorbed on nanoparticle surfaces forming a "protein corona". ${ }^{26,43}$ This natural phenomenon affects the surface charge and hence the colloidal stability of the nanoparticles, which can either be favored or unfavored depending, for example, on the sign of the electric charge of the externally grafted biopolymer. ${ }^{26}$

Gold nanoparticles (GNPs) are other nanodevices widely exploited in nanomedicine. GNPs are characterized by a surface plasmon frequency in the visible range, which makes them suitable for a wide range of applications, ranging from therapeutic treatments (i.e., photothermal therapy ${ }^{44}$ ) to diagnostic imaging or, more interestingly, "theranostics", which is the combination of therapy and diagnostics. ${ }^{45-47}$

The purpose of this work is to combine MSNs, proteins, and GNPs within a single multicomponent system (Scheme 1). Zhan et al. used mesoporous silica-encapsulated gold nanorods bioconjugated with antibodies to create a multifunctional system for imaging of cancer cells. ${ }^{48}$ Croissant et al. prepared a $\mathrm{pH}$-responsive drug delivery system constituted by negatively charged BSA-gold clusters (AuNC@BSA), which interacted with the positively charged amino-functionalized mesoporous silica $\left(\mathrm{MSN}-\mathrm{NH}_{3}^{+}\right)$through electrostatic forces. At acidic $\mathrm{pH}$, the AuNCs@BSA desorbed from the silica surface, thus allowing the release of the drug molecules by the pores. ${ }^{10}$ Here, we use MCM-41-type MSNs due to their ability to act as potential nanocarriers. MSNs are covalently coated by two model proteins, namely, bovine serum albumin (BSA) to provide stability and biocompatibility to the MSNs within the hematic fluid and lysozyme (LYZ) as a model antimicrobial protein. $^{49,50}$ In addition, $20 \mathrm{~nm}$ nearly spherical GNPs are adsorbed on the protein-conjugated MSNs. The resulting multicomponent nano-bioconjugates are characterized by several physicochemical techniques, namely, small angle $\mathrm{X}$ rays scattering (SAXS), transmission electron microscopy (TEM), electrophoretic light scattering (ELS), $\mathrm{N}_{2}$-physisorption, thermogravimetric analysis (TGA), and Fourier transform infrared (FTIR) spectroscopy. In particular, fluorescence spectroscopy and surface-enhanced Raman spectroscopy (SERS) allowed to shed light on the mechanism of proteinGNP interaction. The assembled multicomponent silicaprotein-gold nano-bioconjugate represents a prospective nanodevice for theranostic applications.

\section{RESULTS AND DISCUSSION}

2.1. Characterization of $\mathrm{MSN}-\mathrm{NH}_{2}$. Amino-functionalized mesoporous silica nanoparticles $\left(\mathrm{MSN}-\mathrm{NH}_{2}\right)$ were synthesized as a first step in the design of multicomponent nano-bioconjugates. Figure 1 shows the structural and textural characterization of an MSN- $\mathrm{NH}_{2}$ sample. The TEM image displays the occurrence of nearly spherical silica particles with a size of about 100-120 nm and with a well-defined porosity consisting of parallel channels with a hexagonal arrangement of pores (Figure 1A). The SAXS pattern of the MSN- $\mathrm{NH}_{2}$ sample, shown in Figure $1 \mathrm{~B}$, displays the typical pattern observed for hexagonal $(P 6 \mathrm{~mm})$ mesoporous structures, represented by an intense peak, due to the reflection of 10 plane, and two weak peaks due to the reflection of 11 and 20 planes, respectively. The resulting lattice parameter, $a$, has a value of $46.5 \AA . \mathrm{N}_{2}$ adsorption/desorption isotherm is of a type IV (Figure 1C), resulting in a surface area $\left(S_{\mathrm{BET}}\right)$ of $942 \mathrm{~m}^{2} / \mathrm{g}$ and a pore volume $\left(V_{\mathrm{p}}\right)$ of $1.08 \mathrm{~cm}^{3} / \mathrm{g}$. Pore size distribution (Figure 1D) has a maximum at $25.8 \AA$ (Table S1, Supporting Information).

Thermogravimetric analysis (TGA) of the $\mathrm{MSN}-\mathrm{NH}_{2}$ sample was then carried out. Curves in Figure 2 show that MSN- $\mathrm{NH}_{2}$ has a mass loss at about $100{ }^{\circ} \mathrm{C}$, attributed to the loss of adsorbed water, and then an additional mass loss above 

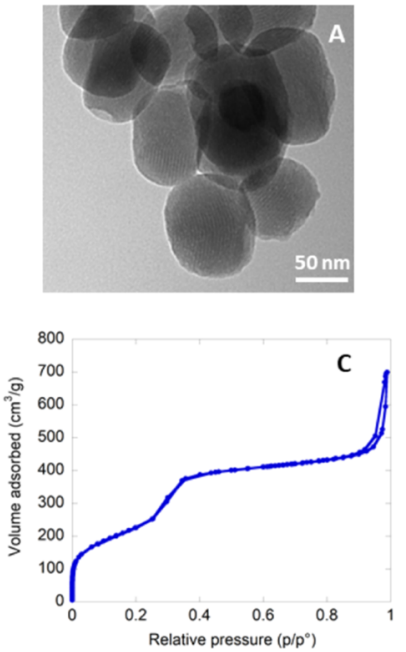

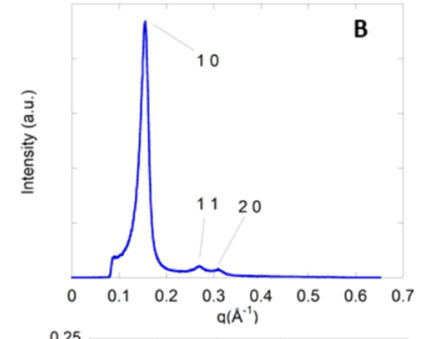

0.25

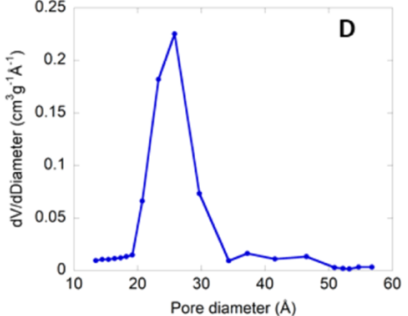

Figure 1. Characterization of MSN- $\mathrm{NH}_{2}$ by (A) TEM, (B) SAXS, (C) $\mathrm{N}_{2}$-physisorption isotherm, and (D) pore size distribution.

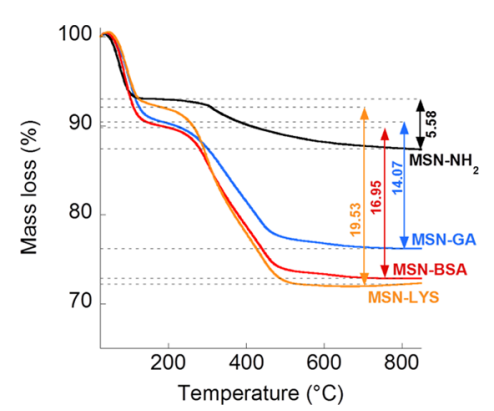

Figure 2. Thermogravimetric analysis. Mass loss (\%) profiles as a function of the temperature of MSN- $\mathrm{NH}_{2}, \mathrm{MSN}-\mathrm{GA}, \mathrm{MSN}-\mathrm{LYZ}$, and MSN-BSA samples.

$200{ }^{\circ} \mathrm{C}$ (5.7\%). This confirms the occurrence of organic functional groups on the mesoporous silica surface.

2.2. Characterization of $\mathrm{MSN}-\mathrm{NH}_{2}-$ Protein NanoBioconjugates. Amino-functionalized MSNs were conjugated with BSA and lysozyme proteins using glutaraldehyde as the linker. MSN-protein conjugation was qualitatively assessed by FTIR spectroscopy and quantitatively by TGA.

Figure S1 (Supporting Information) shows the FTIR spectra of MSN-BSA and MSN-LYZ conjugates. Both samples show a peak at $1642 \mathrm{~cm}^{-1}$ due to amide $\mathrm{I}$, typical of the $\mathrm{C}=\mathrm{O}$ stretching of peptide bonds. ${ }^{26}$ Usually, proteins adsorbed on mesoporous silica show a more intense amide I band and a less intense amide II band. ${ }^{31}$ Here, the low intensity of amide I and the absence of the amide II peak are likely due to a low protein loading. This result is expected. Indeed, MSNs pore diameter (about $2 \mathrm{~nm}$ ) is smaller than lysozyme $(3.8 \mathrm{~nm})^{51}$ and BSA $(7.2 \mathrm{~nm})^{52}$ size; thus, adsorption can occur only at the external surface of MSNs, which is only a small fraction of the whole surface area.

Figure 2 shows the mass loss (\%) profiles obtained at temperatures above $200{ }^{\circ} \mathrm{C}$, which can be ascribed to the burning of organics (mass loss \% values obtained at temperatures $<200{ }^{\circ} \mathrm{C}$ are associated with the loss of water). Considering the progressive increase in mass loss at the different steps of bioconjugation, the amount of adsorbed proteins was calculated to be 55 and $29 \mathrm{mg} / \mathrm{g}$ for lysozyme (MSN-LYZ) and BSA (MSN-BSA), respectively (Table 1). These low loadings are consistent with FTIR spectra in Figure S1. Table 1 reports TGA and $\zeta$-potential data also for the glutaraldehyde-MSN conjugate (MSN-GA) to describe the changes in mass loss and surface charge during the various steps.

Electrophoretic light scattering (ELS) technique was used to measure $\zeta$-potential $(\zeta)$ values of MSN-based samples prior to and after protein immobilization at two different $\mathrm{pH}$ values, neutral $(\mathrm{pH}=7)$ and acidic $(\mathrm{pH}=4)$. The acidic value of $\mathrm{pH}$ was chosen to provide further proof of MSNs surface modification due to the different responses of $\mathrm{MSN}-\mathrm{NH}_{2}$, MSN-BSA, and MSN-LYZ to $\mathrm{pH}$ changes. As expected, we found a highly positive $\zeta$ at $\mathrm{pH} 4(+31 \mathrm{mV})$ and an almost neutral value at $\mathrm{pH} 7(+2 \mathrm{mV})$ for $\mathrm{MSN}-\mathrm{NH}_{2}$. A similar trend is expected for MSN-LYZ samples due to the high isoelectric point $($ IEP $\approx 11)$ of lysozyme. Finally, due to IEP $(\approx 4.7)$ of BSA, we found a sign change for $\zeta$ going from $\mathrm{pH} 7(-12 \mathrm{mV})$ to $\mathrm{pH} 4(+18 \mathrm{mV})$. Hence, $\zeta$ values listed in Table 1 are consistent with the occurrence of a layer of BSA and LYZ proteins covering the MSN particle surface.

2.3. TEM Characterization of MSN-Proteins-GNPs Nano-Bioconjugates. Results described in the previous paragraph, particularly, the change of $\zeta$ values, demonstrate that BSA and lysozyme proteins were successfully immobilized on the external MSNs surface. The occurrence of adsorbed proteins on the surface is particularly important to achieve the goal of this work, that is, the realization of nano-bioconjugates constituted by MSN-protein-GNPs. This was done by dispersing MSN-protein conjugates in a solution of colloidal gold nanoparticles, as described in Section 2.2. The obtainment of the nano-bioconjugates was then confirmed by TEM analysis. Figure 3 shows the TEM images of MSN samples treated with GNPs in the presence of immobilized proteins on the surface. Representative TEM images of control samples where protein-free MSN was treated with GNPs are reported in Figure S2.

Table 1. Mass Loss \% Values Obtained by Thermogravimetric Analysis ${ }^{a}$

\begin{tabular}{|c|c|c|c|c|c|c|}
\hline \multirow[b]{2}{*}{ sample } & \multicolumn{2}{|c|}{ mass loss $(\%)$} & \multicolumn{2}{|c|}{$\zeta(\mathrm{mV})$} & \multirow[b]{2}{*}{ loading $\left(\mathrm{mg} \mathrm{g}^{-1}\right)$} & \multirow[b]{2}{*}{ molar ratio $\left(\mathrm{mol} \mathrm{g}^{-1}\right)$} \\
\hline & $T<200{ }^{\circ} \mathrm{C}$ & $T>200{ }^{\circ} \mathrm{C}$ & ${ }^{b} \mathrm{pH}=4$ & ${ }^{c} \mathrm{pH}=7$ & & \\
\hline $\mathrm{MSN}-\mathrm{NH}_{2}$ & 7.08 & 5.58 & $+31 \pm 1$ & $+2 \pm 2$ & 56 & $9.66 \times 10^{-4}\left(\mathrm{MM}_{-\mathrm{C}_{3} \mathrm{H}_{6}-\mathrm{NH}_{2}}=58 \mathrm{~g} \mathrm{~mol}^{-1}\right)$ \\
\hline MSN-GA & 9.76 & 14.07 & $+8 \pm 1$ & $-2 \pm 1$ & $85^{d}$ & $8.49 \times 10^{-4}\left(\mathrm{MM}_{\mathrm{GA}}=100.11 \mathrm{~g} \mathrm{~mol}^{-1}\right)$ \\
\hline MSN-BSA & 11.22 & 16.95 & $+18 \pm 2$ & $-12 \pm 1$ & $29^{e}$ & $4.36 \times 10^{-7}\left(\mathrm{MM}_{\mathrm{BSA}}=66463 \mathrm{~g} \mathrm{~mol}^{-1}\right)$ \\
\hline MSN-LYZ & 8.15 & 19.53 & $+29 \pm 2$ & $+1 \pm 1$ & $55^{e}$ & $1.90 \times 10^{-5}\left(\mathrm{MM}_{\mathrm{LYS}}=14400 \mathrm{~g} \mathrm{~mol}^{-1}\right)$ \\
\hline
\end{tabular}

${ }^{a} \zeta$-Potential $(\zeta)$ values of functionalized MSN samples after each step of surface functionalization. TGA and $\zeta$ data are listed also for the MSNglutaraldehyde intermediate (MSN-GA). ${ }^{b}$ Citrate buffer $0.1 \mathrm{M} .{ }^{c}$ Phosphate buffer $0.1 \mathrm{M} . \frac{d \text { (massloss } \%)_{\mathrm{MSN}-\mathrm{GA}}-(\text { mass loss } \%)_{\mathrm{MSN}-\mathrm{NH}_{2}}}{100}\left(T>200{ }^{\circ} \mathrm{C}\right)$. $\underline{e(\text { mass loss \% })_{\text {MSN-PROTEIN }}-(\text { mass loss \% })_{\mathrm{MSN}-\mathrm{GA}}}\left(T>200{ }^{\circ} \mathrm{C}\right)$. 

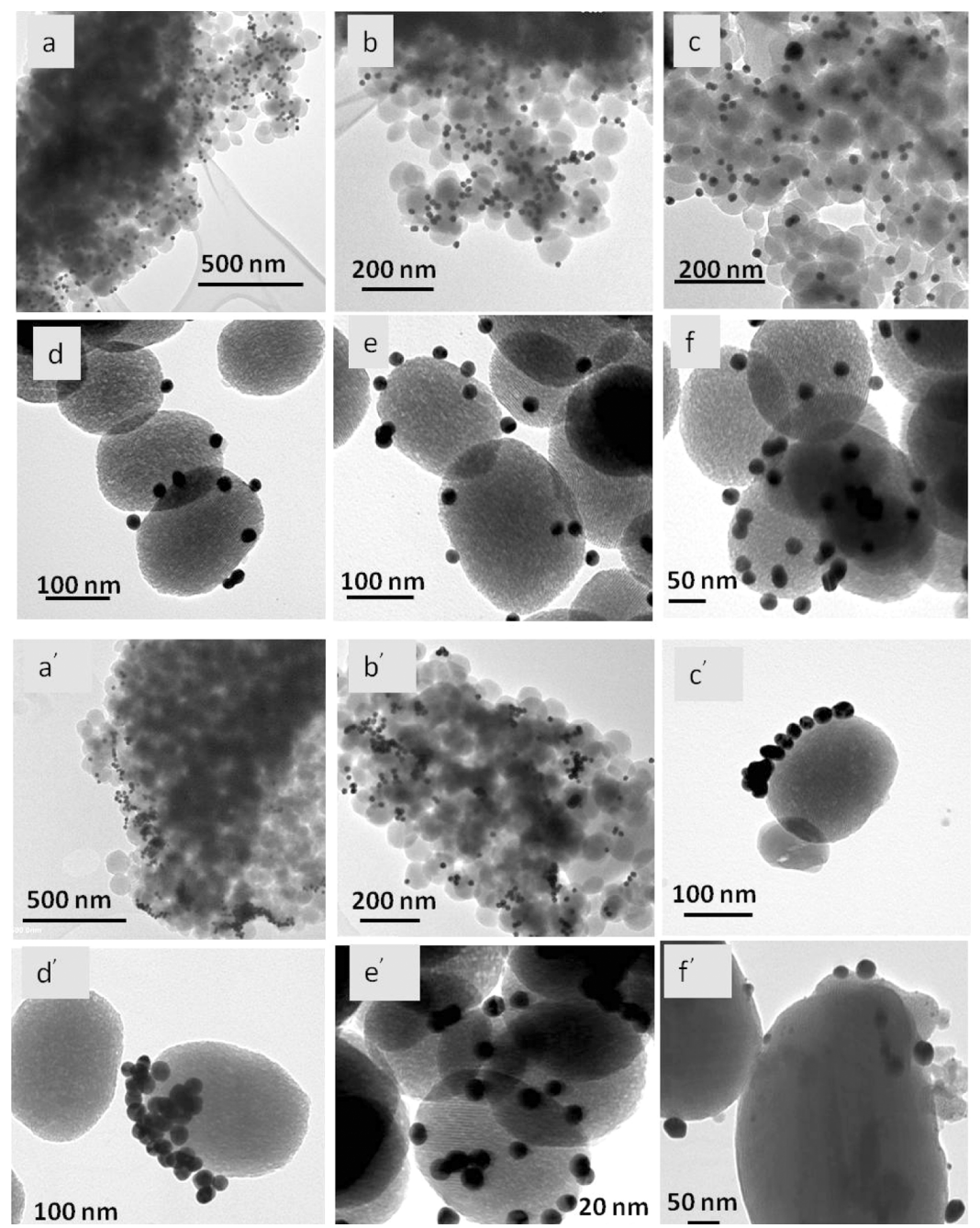

Figure 3. TEM images of $(a-f)$ MSN-BSA and $\left(a^{\prime}-f^{\prime}\right)$ MSN-LYZ treated with GNPs. Control sample (protein-free) images are shown in Figure S2 (Supporting Information).
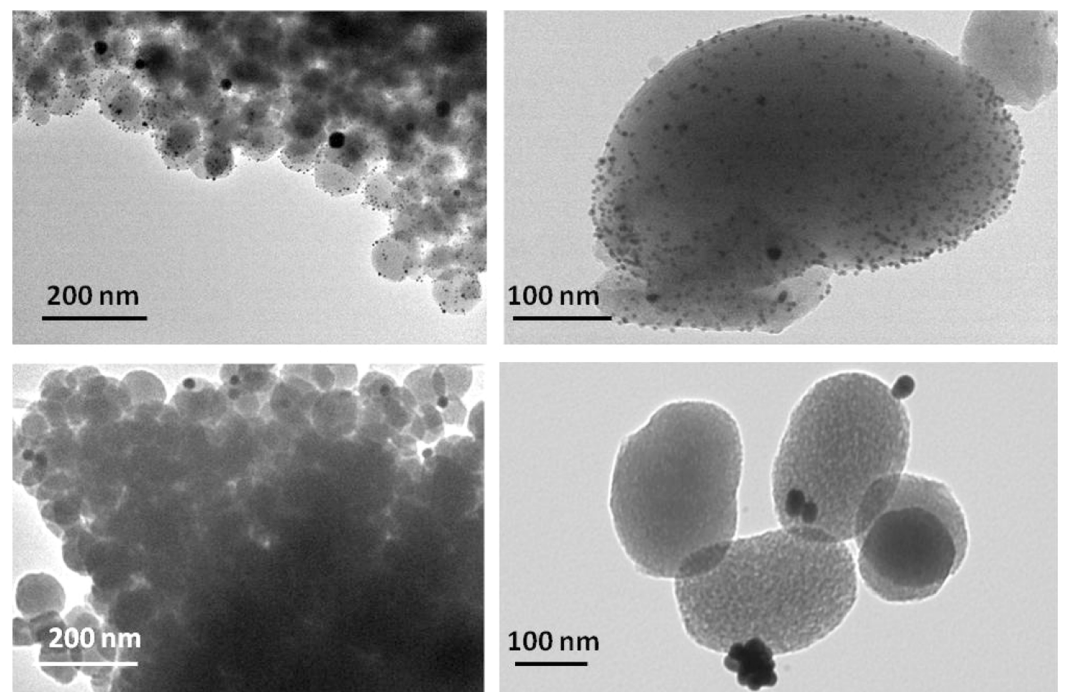

Figure 4. TEM images of MSN- $\mathrm{NH}_{2}$ (protein-free) particles loaded with $5 \mathrm{~nm}$ (top) and $20 \mathrm{~nm}$ (bottom) GNP.

In particular, the nanostructures obtained by mixing a GNP solution with MSN-BSA and MSN-LYZ are shown in Figure $3 a-f$ and $a^{\prime}-f^{\prime}$, respectively. Interestingly, in this case, TEM images also allow the proteins attached to the silica surface to be located, as the presence of GNPs on the silica surface indirectly indicates the presence of proteins at the same site. ${ }^{53}$ It can be observed that various GNPs, which appear as dark dots, are in contact with the MSNs surface. On the contrary, 

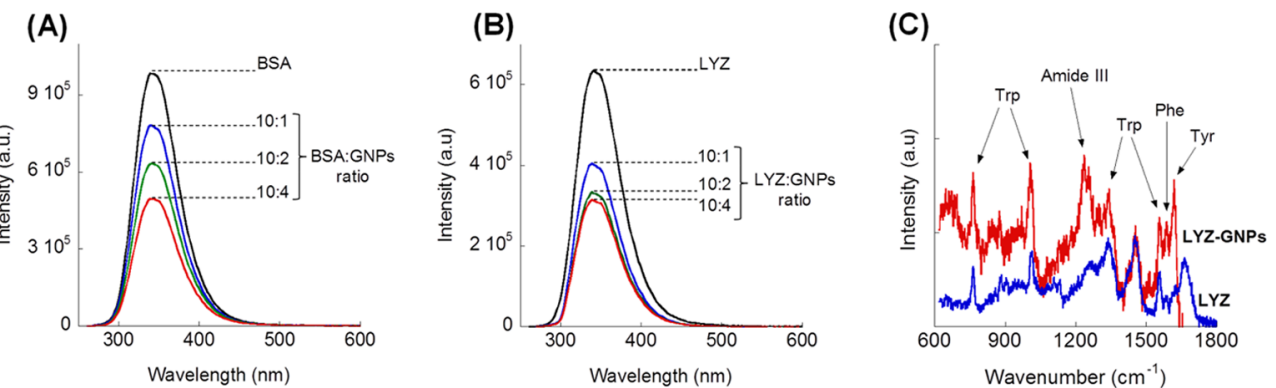

Figure 5. Fluorescence spectra of (A) BSA/GNPs and (B) LYZ/GNPs aqueous solutions with different volume ratios. (C) Raman spectrum of LYZ/GNPs conjugate solution.

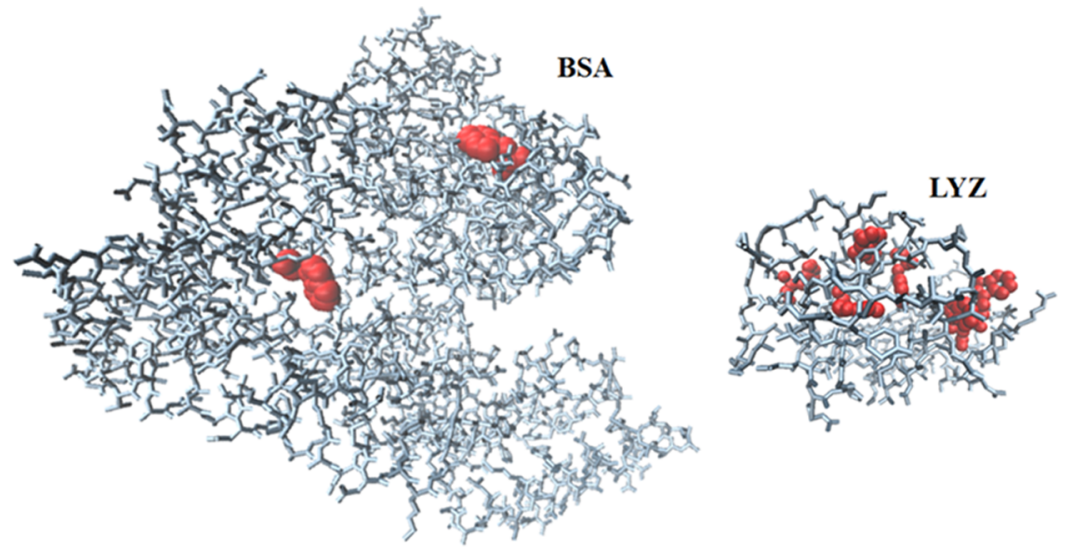

Figure 6. Structure of BSA (PDB file: 3V03) ${ }^{65}$ and lysozyme (PDB file: 1LYZ). ${ }^{66}$ Tryptophan residues are colored in red. Images obtained with visual molecular dynamics software.

protein-free MSN- $\mathrm{NH}_{2}$ samples show only few GNPs at the particle surface (Figure S2, Supporting Information). This indicates that $\mathrm{MSN}-\mathrm{NH}_{2}$ particles have very low reactivity toward GNPs. It should be noted that many reports provide evidence that amino-coated silica nanoparticles are able to interact with GNPs, ${ }^{54-58}$ and indeed, this discrepancy might be due to GNP size effects. Figure 4 compares $\mathrm{MSN}-\mathrm{NH}_{2}$ when reacted with small GNPs $(5 \mathrm{~nm})$ and larger GNPs (20 $\mathrm{nm}$ ), such as those investigated in this work. It appears that smaller GNPs significantly interact with aminopropyl-coated silica, whereas larger GNPs have scarce affinity for $\mathrm{MSN}-\mathrm{NH}_{2}$ (Figure 4).

We recently investigated the formation of the protein corona on biopolymer (either hyaluronic acid or chitosan) functionalized MSNs. ${ }^{26}$ The strategy for its visualization through TEM was the use of commercial conjugates between the BSA protein and GNPs. With this method, the black spots in the TEM images corresponded univocally to the BSA molecules adsorbed on biopolymer-functionalized MSNs surface. Here, instead, the proteins were previously immobilized on MSNs and only then GNPs were left to interact with the MSNprotein bioconjugates. The TEM images clearly suggest that large $(20 \mathrm{~nm})$ GNPs can interact with MSNs only in the presence of surface-bound proteins. The different reactivities with GNPs observed for MSN-protein conjugates and MSN$\mathrm{NH}_{2}$ control samples suggest the involvement in the interaction of some specific amino acid residues occurring at the protein surface. This deserves a deeper investigation.

2.4. Spectroscopic Investigation of Protein-GNPs Interactions in Aqueous Solution. Previous studies have shown that cysteine, lysine, and tryptophan residues can interact with GNPs. ${ }^{59}$ Iosin et al. used UV-vis spectroscopy to verify protein/GNPs interactions ${ }^{60}$ by monitoring either the intensity or the position of the localized surface plasmon resonance band of GNPs at around $420 \mathrm{~nm}$. Winuprasith et al. used surface-enhanced Raman spectroscopy (SERS) to observe the enhancement of Raman bands of the amino acid residues (likely cysteine, tryptophan, etc.) involved in the interaction with the GNPs. ${ }^{61}$ Finally, Vaishanav et al. used fluorescence spectroscopy to investigate protein/GNPs interactions. ${ }^{62}$ Based on these studies, we used fluorescence spectroscopy to understand the interaction between GNPs and LYZ or BSA proteins in aqueous solution. After an excitation with a $250 \mathrm{~nm}$ radiation, the fluorescence spectra of BSA and lysozyme solutions, at a fixed concentration of $10 \mathrm{mg} / \mathrm{mL}$, were recorded after addition of increasing volumes of a GNP solution. The fluorescence spectra, shown in Figure 5, display a peak at the wavelength $340 \mathrm{~nm}$ due to the emission of a tryptophan residue. ${ }^{60}$ The addition of GNPs results in a quenching of the fluorescence intensity. This effect may be ascribed to the formation of nonfluorescent GNPs-protein conjugates (static quenching), thus suggesting that the tryptophan residues are involved in the interaction with GNPs. ${ }^{63,64}$

The fluorescence spectra of GNPs-BSA conjugates undergo a lower quenching compared to those of GNPs-lysozyme conjugates, for the same concentration of GNPs. This fact suggests that the GNPs could display stronger interactions with lysozyme than with BSA. This different interaction may be due to the structural difference between the two proteins. Indeed, lysozyme possesses six tryptophan residues, whereas BSA only two (Figure 6). Moreover, lysozyme is smaller than BSA; thus, the odds that such residues are sufficiently exposed 
to establish an interaction with the GNPs are considerably higher. This different abundances and availability of tryptophan residues may be the reason why the fluorescence spectra of GNPs-LYZ conjugates undergo a higher quenching compared to those of GNPs-BSA conjugates.

The effect of BSA induced by GNPs was studied through SERS by Iosin et al. ${ }^{67}$ They found that the occurrence of GNPs modifies the Raman spectrum of BSA, causing an increase in the intensity of the bands (SERS effect) of tryptophan residues. This again confirms that tryptophan is significantly involved in the interaction with GNPs. Figure 5C shows the Raman spectrum of lysozyme solution compared to that obtained after the addition of GNPs. Similar to what was observed for BSA, ${ }^{67}$ also for lysozyme the Raman signals of tryptophan are enhanced in the presence of GNPs (Figure 5C). Even other signals turned out to be enhanced, at 1583 and $1616 \mathrm{~cm}^{-1}$, which are, respectively, related to phenylalanine and tyrosine. ${ }^{68}$ Nevertheless, this fact may likely be due only to the spatial proximity of the latter residues to some tryptophan amino acids. Remarkably, findings from different techniques converge to very similar conclusions.

\section{CONCLUSIONS}

In this work, we have addressed the design of multicomponent nano-bioconjugates as a mean to expand the range of available nanostructures for possible biomedical use. In particular, we have shown that mesoporous silica nanoparticles with a hexagonal structure could be covalently conjugated to two relevant proteins, such as bovine serum albumin and lysozyme. The conjugation with BSA and lysozyme, quantified by thermogravimetric analysis, varies the surface properties as shown by $\zeta$-potential measurements. Protein conjugation also modifies surface reactivity, enabling effective interaction with gold nanoparticles. TEM clearly points out that the bare nanoparticles $\left(\mathrm{MSN}-\mathrm{NH}_{2}\right)$ poorly interact with large $(20 \mathrm{~nm})$ GNPs, as compared to protein-coated MSNs. TEM images of the MSN-protein-GNP nano-bioconjugates indicate a more specific interaction promoted by the protein coating. Indeed, TEM images of GNPs located on the MSNs surface provide indirect information on protein surface location. The promising results obtained for these nano-bioconjugates may be related to the tryptophan-mediated interaction between proteins and GNPs, as demonstrated by fluorescence and Raman spectroscopies. Further work will be needed to investigate the application of the obtained nano-bioconjugates in nanomedicine as biocompatible theranostic devices.

\section{EXPERIMENTAL SECTION}

4.1. Chemicals. Tetraethylorthosilicate (98\%), 3-aminopropyltriethoxysilane (APTES, 97\%), glutaraldehyde (50\% aqueous solution $\mathrm{w} / \mathrm{v}$ ), cetyltrimethylammonium bromide, gold colloid solutions (GNP, average size 20 and $5 \mathrm{~nm}$ ), sodium hydroxide $(\mathrm{NaOH}, 97 \%)$, anhydrous toluene $(99.8 \%)$, methanol (99.8\%), acetone (99\%), bovine serum albumin (BSA), and disodium hydrogen phosphate $(\geq 99 \%)$ were purchased from Sigma-Aldrich. Sodium dihydrogen phosphate was purchased from J.T. Baker.

4.2. Preparation of MSN-Protein-GNPs Nano-Bioconjugates. Aminopropyl-functionalized mesoporous silica nanoparticles $\left(\mathrm{MSN}-\mathrm{NH}_{2}\right)$ were prepared following the method reported in ref 69. Then, MSN-protein-GNP nano-bioconjugates were prepared. Preliminary studies were carried out to find the conditions that avoid the formation of MSN aggregates. A mass of $20 \mathrm{mg}$ of $\mathrm{MSN}-\mathrm{NH}_{2}$ was dispersed in $2 \mathrm{~mL}$ of $0.1 \mathrm{M}$ phosphate buffer at $\mathrm{pH} 8$ with the help of an ultrasonic bath. A volume of $8 \mu \mathrm{L}$ of glutaraldehyde (GA) was then added, and the mixture obtained was left under mild rotation $(60 \mathrm{rpm})$ for $45 \mathrm{~min}$. The suspension was centrifuged (4500 rpm for $15 \mathrm{~min}$ ), and the liquid phase was removed from the solid through a Pasteur pipette. The remaining solid (MSN-GA) was washed twice with phosphate buffer solution ( $0.1 \mathrm{M}$ at $\mathrm{pH} 8)$, dispersed under vigorous stirring and then recovered by centrifugation $(4500 \mathrm{rpm}$ for 15 $\mathrm{min}$ ), and then suspended in the protein solution prepared in phosphate buffer (0.1 M at $\mathrm{pH} 8)$. In the case of lysozyme, 3 $\mathrm{mL}$ of a $5 \mathrm{mg} / \mathrm{mL}$ lysozyme solution was used, whereas $1.5 \mathrm{~mL}$ of a $10 \mathrm{mg} / \mathrm{mL}$ was used for BSA. The suspension was left under mild rotation $(60 \mathrm{rpm})$ overnight. After centrifugation (4500 $\mathrm{rpm}$ for $15 \mathrm{~min}$ ), the retrieved solid fraction was washed twice with phosphate buffer solution $(0.1 \mathrm{M}$ at $\mathrm{pH} 8)$ and dried under vacuum. The complete MSN-protein-GNP nano-bioconjugates were assembled by adding $700 \mu \mathrm{L}$ of colloidal gold solution to $2 \mathrm{mg}$ of obtained MSN-protein conjugates and leaving the dispersion under rotation $(60 \mathrm{rpm})$ overnight. Then, the liquid fraction was removed after centrifugation (4500 $\mathrm{rpm}$ for $15 \mathrm{~min}$ ). The recovered solid was dried under vacuum and observed by transmission electron microscopy.

4.3. Physicochemical Characterization of MSNs, MSN-Protein, and MSN-Protein-GNP Samples. The structure of $\mathrm{MSN}-\mathrm{NH}_{2}$ was verified by SAXS, whereas specific surface area and pore size distribution were obtained by $\mathrm{N}_{2}$ adsorption/desorption isotherms at $77 \mathrm{~K}$ recorded on a Micromeritics ASAP2020 using the Brunauer-Emmett-Teller (BET) and Barrett-Joyner-Halenda methods, ${ }^{70}$ respectively. Transmission electron microscopy (TEM) images were recorded on a Hitachi H-7000 equipped with a thermionic $\mathrm{W}$ filament running at $100 \mathrm{kV}$. Images were collected by a AMT DVC $(2048 \times 2048$ pixel $)$ CCD camera. Samples for observation were obtained by direct deposition of the finely ground powders on a carbon-coated copper grid. Additional investigation was performed on a JEM 1400 Plus TEM microscope. Thermogravimetric analysis (TGA) was carried out through a Mettler Toledo TGA/SDTA 851. The scans were collected under oxygen as a reactive gas and nitrogen as a carrier gas in the range $25-1000{ }^{\circ} \mathrm{C}$. FTIR spectra were obtained through a Bruker Tensor 27 spectrometer equipped with a Platinum-ATR accessory and a DTGS (deuterated triglycine sulfate) detector. $\zeta$-Potential $(\zeta)$ of MSNs was measured using a Zetasizer Nano ZSP (Malvern Instruments) in backscatter configuration $\left(\theta=173^{\circ}\right)$, at a laser wavelength of $\lambda=633 \mathrm{~nm}$. The scattering cell temperature was fixed at 25 ${ }^{\circ} \mathrm{C}$, and the data were analyzed with the Zetasizer software 7.03 version. The sample was prepared by suspending MSNs $(1 \mathrm{mg} / \mathrm{mL})$ in $0.1 \mathrm{M}$ citrate buffer solution and $0.1 \mathrm{M}$ phosphate buffer solution to obtain the $\zeta$-potential values at $\mathrm{pH} 4$ and $\mathrm{pH} 7$, respectively. Samples were sonicated for 30 min and left under stirring overnight, and then electrophoretic mobility measurements were carried out. $\zeta$-Potential values were calculated by means of the Henry equation using water as the dispersant medium $\left(\varepsilon_{\mathrm{r}}=78.5\right.$ and $\eta=0.89 \mathrm{cP}$ at $\left.25^{\circ} \mathrm{C}\right)$ and $f(\kappa a)=1.5$ (Smoluchowski approximation).

4.4. Spectroscopic Characterization of GNP-Protein Conjugates. GNP-protein conjugates were prepared by adding to $500 \mu \mathrm{L}$ of $10 \mathrm{mg} / \mathrm{mL}$ protein solution in $0.1 \mathrm{M}$ 
phosphate buffer at $\mathrm{pH} 7$ increasing amounts of GNPs solution (50, 100, and $200 \mu \mathrm{L}$ ). The photoluminescence (PL) spectra of the conjugates with different $\mathrm{GNP}$-protein ratios thus obtained were recorded by exciting GNP-protein samples with the emission at $250 \mathrm{~nm}$ of an optical parametric oscillator with a frequency doubler device (Spectra Physics MOPO), seeded by a pulsed Nd-YAG laser (Spectra Physics Quanta Ray PRO-270). The excitation pulse energy was of about $1 \mathrm{~mJ} /$ pulse, and pulse-width at half-maximum was $8 \mathrm{~ns}$ with $10 \mathrm{~Hz}$ repetition rate. PL measurements were performed in backscattering geometry, focusing the emitted light signal onto the entrance slit of a monochromator (ARC Spectra Pro 300i) with a spectral bandwidth of $12 \mathrm{~nm}$. The signal was detected by a gatable intensified CCD (Princeton Instruments PIMAX). Raman scattering measurements were carried out in backscattering geometry with the $632 \mathrm{~nm}$ line of a $\mathrm{He}-\mathrm{Ne}$ laser. Measurements were performed in air at room temperature with a triple spectrometer Jobin-Yvon Dilor integrated system with a spectral resolution of about $1 \mathrm{~cm}^{-1}$.

\section{ASSOCIATED CONTENT}

\section{S Supporting Information}

The Supporting Information is available free of charge on the ACS Publications website at DOI: 10.1021/acsomega.9b01240.

Textural and structural parameters of $\mathrm{MSN}-\mathrm{NH}_{2}$; FTIR spectra of MSN-BSA and MSN-LYZ samples; and TEM images of $\mathrm{MSN}-\mathrm{NH}_{2}$ control samples treated with GNPs (PDF)

\section{AUTHOR INFORMATION}

\section{Corresponding Author}

*E-mail: asalis@unica.it. Tel: +39 070675 4362. Fax: +39070 6754388.

\section{ORCID}

Maria F. Casula: 0000-0002-2973-0002

Marco Piludu: 0000-0003-1917-0475

Pier Carlo Ricci: 0000-0001-6191-4613

Maura Monduzzi: 0000-0003-0200-7700

Andrea Salis: 0000-0001-5746-2693

\section{Present Address}

${ }^{\perp}$ Department of Mechanical, Chemical and Materials Engineering, University of Cagliari, Via Marengo, 3, I-09123 Cagliari, Italy (M.F.C.).

\section{Notes}

The authors declare no competing financial interest.

\section{ACKNOWLEDGMENTS}

FIR 2017-2018 and Fondazione di Sardegna/Regione Autonoma della Sardegna (CUP F72F16003070002) are acknowledged for financial support. A.S. thanks FFABR 2017 (MIUR). M.V.-R thanks the European Research Council (Advanced Grant VERDI; ERC-2015-AdG Proposal No. 694160). G.R.D. thanks MIUR-PON-RI 2014-2020 (DOT1304455-1) for financing her $\mathrm{PhD}$ scholarship. We acknowledge the CeSAR (Centro Servizi d'Ateneo per la Ricerca) of the University of Cagliari, Italy for access to a JEM 1400 Plus TEM microscope.

\section{REFERENCES}

(1) Wicki, A.; Witzigmann, D.; Balasubramanian, V.; Huwyler, J. Nanomedicine in Cancer Therapy: Challenges, Opportunities, and Clinical Applications. J. Controlled Release 2015, 200, 138-157.

(2) Chang, E. H.; Harford, J. B.; Eaton, M. A. W.; Boisseau, P. M.; Dube, A.; Hayeshi, R.; Swai, H.; Lee, D. S. Nanomedicine: Past, Present and Future - A Global Perspective. Biochem. Biophys. Res. Commun. 2015, 468, 511-517.

(3) Monduzzi, M.; Lampis, S.; Murgia, S.; Salis, A. From SelfAssembly Fundamental Knowledge to Nanomedicine Developments. Adv. Colloid Interface Sci. 2014, 205, 48-67.

(4) Chen, S.; Zhang, Q.; Hou, Y.; Zhang, J.; Liang, X. J. Nanomaterials in Medicine and Pharmaceuticals: Nanoscale Materials Developed with Less Toxicity and More Efficacy. Eur. J. Nanomed. 2013, 5, 61-79.

(5) Li, Z.; Barnes, J. C.; Bosoy, A.; Stoddartbc, J. F.; Zink, J. I. Mesoporous Silica Nanoparticles in Biomedical Applications. Chem. Soc. Rev. 2012, 41, 2590-2605.

(6) Mamaeva, V.; Sahlgren, C.; Lindén, M. Mesoporous Silica Nanoparticles in Medicine-Recent Advances. Adv. Drug Delivery Rev. 2013, 65, 689-702.

(7) Argyo, C.; Weiss, V.; Bra, C.; Bein, T. Multifunctional Mesoporous Silica Nanoparticles as a Universal Platform for Drug Delivery. Chem. Mater. 2014, 26, 435-451.

(8) Wang, Y.; Zhao, Q.; Han, N.; Bai, L.; Li, J.; Liu, J.; Che, E.; Hu, L.; Zhang, Q.; Jiang, T.; et al. Mesoporous Silica Nanoparticles in Drug Delivery and Biomedical Applications. Nanomed. Nanotechnol. Biol. Med. 2015, 11, 313-327.

(9) Manzano, M.; Vallet-Regí, M. Mesoporous Silica Nanoparticles in Nanomedicine Applications. J. Mater. Sci. Mater. Med. 2018, 29, 65.

(10) Yang, Y.-W. Towards Biocompatible Nanovalves Based on Mesoporous Silica Nanoparticles. Med. Chem. Commun. 2011, 2, 1033-1049.

(11) Nairi, V.; Medda, L.; Monduzzi, M.; Salis, A. Adsorption and Release of Ampicillin Antibiotic from Ordered Mesoporous Silica. J. Colloid Interface Sci. 2017, 497, 217-225.

(12) Croissant, J. G.; Zhang, D.; Alsaiari, S.; Lu, J.; Deng, L.; Tamanoi, F.; Almalik, A. M.; Zink, J. I.; Khashab, N. M. Protein-Gold Clusters-Capped Mesoporous Silica Nanoparticles for High Drug Loading, Autonomous Gemcitabine/Doxorubicin Co-Delivery, and in-Vivo Tumor Imaging. J. Controlled Release 2016, 229, 183-191.

(13) Tsai, C. H.; Vivero-Escoto, J. L.; Slowing, I. I.; Fang, I.; Trewyn, B. G.; Lin, V. S. Biomaterials Surfactant-Assisted Controlled Release of Hydrophobic Drugs Using Anionic Surfactant Templated Mesoporous Silica Nanoparticles. Biomaterials 2011, 32, 6234-6244.

(14) Vivero-Escoto, J. L.; Slowing, I. I.; Trewyn, B. G.; Lin, V. S.; Memoriam, I.; Victor, P. Mesoporous Silica Nanoparticles for Intracellular Controlled Drug Delivery. Small 2010, 6, 1952-1967.

(15) Knežević, N. Z.; Trewyn, B. G.; Lin, V. S.-Y. Functionalized Mesoporous Silica Nanoparticle-Based Visible Light Responsive Controlled Release Delivery System. Chem. Commun. 2011, 47, 2817-2819.

(16) Aznar, E.; Oroval, M.; Pascual, L.; Murguía, J. R.; MartínezMáñez, R.; Sancenón, F. Gated Materials for On-Command Release of Guest Molecules. Chem. Rev. 2016, 116, 561-718.

(17) Lou, X.; Li, Y.; Yang, Y. Gated Materials: Installing Macrocyclic Arenes-Based Supramolecular Nanovalves on Porous Nanomaterials for Controlled Cargo Release. Biotechnol. J. 2019, 14, No. 1800354.

(18) Wang, X.; Tan, L.-L.; Yang, Y.-W. Controlled Drug Release System Based on Mesoporous Silica Capped by Gold Nanoparticles. Acta Chim. Sin. 2016, 74, 303-311.

(19) Hu, X.; Spada, S.; White, S.; Hudson, S.; Magner, E.; Wall, J. G. Adsorption and Activity of a Domoic Acid Binding Antibody Fragment on Mesoporous Silicates. J. Phys. Chem. B 2006, 110, 18703-18709.

(20) Prabhakar, N.; Zhang, J.; Desai, D.; Casals, E.; Gulin-Sarfraz, T.; Näreoja, T.; Westermarck, J.; Rosenholm, J. M. StimuliResponsive Hybrid Nanocarriers by Controllable Integration of 
Hyperbranched PEI on Mesoporous Silica Particles for Sustained Intracellular siRNA Delivery. Int. J. Nanomed. 2016, 11, 6591-6608. (21) Baeza, A.; Manzano, M.; Colilla, M.; Vallet-Regi, M. Recent Advances in Mesoporous Silica Nanoparticles for Antitumor Therapy: Our Contribution. Biomater. Sci. 2016, 4, 803-813.

(22) Maggini, L.; Cabrera, I.; Ruiz-Carretero, A.; Prasetyanto, E. A.; Robinet, E.; De Cola, L. Breakable Mesoporous Silica Nanoparticles for Targeted Drug Delivery. Nanoscale 2016, 8, 7240-7247.

(23) Beck, M.; Mandal, T.; Buske, C.; Lindén, M. Serum Protein Adsorption Enhances Active Leukemia Stem Cell Targeting of Mesoporous Silica Nanoparticles. ACS Appl. Mater. Interfaces 2017, 9, 18566-18574.

(24) Song, N.; Yang, Y.-W. Molecular and Supramolecular Switches on Mesoporous Silica Nanoparticles. Chem. Soc. Rev. 2015, 44, 34743504.

(25) Salis, A.; Fanti, M.; Medda, L.; Nairi, V.; Cugia, F.; Piludu, M.; Sogos, V.; Monduzzi, M. Mesoporous Silica Nanoparticles Functionalized with Hyaluronic Acid and Chitosan Biopolymers. Effect of Functionalization on Cell Internalization. ACS Biomater. Sci. Eng. 2016, 2, 741-751.

(26) Nairi, V.; Medda, S.; Piludu, M.; Casula, M. F.; Vallet-Regì, M.; Monduzzi, M.; Salis, A. Interactions between Bovine Serum Albumin and Mesoporous Silica Nanoparticles Functionalized with Biopolymers. Chem. Eng. J. 2018, 340, 42-50.

(27) Magner, E. Immobilisation of Enzymes on Mesoporous Silicate Materials. Chem. Soc. Rev. 2013, 42, 6213.

(28) Hartmann, M.; Kostrov, X. Immobilization of Enzymes on Porous Silicas - Benefits and Challenges. Chem. Soc. Rev. 2013, 42, 6277.

(29) Salis, A.; Medda, L.; Cugia, F.; Monduzzi, M. Effect of Electrolytes on Proteins Physisorption on Ordered Mesoporous Silica Materials. Colloids Surf., B 2016, 137, 77-90.

(30) Pitzalis, F.; Monduzzi, M.; Salis, A. A Bienzymatic Biocatalyst Constituted by Glucose Oxidase and Horseradish Peroxidase Immobilized on Ordered Mesoporous Silica. Microporous Mesoporous Mater. 2017, 241, 145-154.

(31) Steri, D.; Monduzzi, M.; Salis, A. Ionic Strength Affects Lysozyme Adsorption and Release from SBA-15 Mesoporous Silica. Microporous Mesoporous Mater. 2013, 170, 164-172.

(32) Medda, L.; Casula, M. F.; Monduzzi, M.; Salis, A. Adsorption of Lysozyme on Hyaluronic Acid Functionalized SBA-15 Mesoporous Silica: A Possible Bioadhesive Depot System. Langmuir 2014, 30, 12996-13004.

(33) Piras, M.; Salis, A.; Piludu, M.; Steri, D.; Monduzzi, M. 3D Vision of Human Lysozyme Adsorbed onto a SBA-15 Nanostructured Matrix. Chem. Commun. 2011, 47, 7338.

(34) Piludu, M.; Medda, L.; Cugia, F.; Monduzzi, M.; Salis, A. Silver Enhancement for Transmission Electron Microscopy Imaging of Antibody Fragment-Gold Nanoparticles Conjugates Immobilized on Ordered Mesoporous Silica. Langmuir 2015, 31, 9458-9463.

(35) Carrillo-carrion, C.; Bocanegra, A. I.; Arnaiz, B.; Feliu, N.; Zhu, D.; Parak, W. J. Triple-Labeling of Polymer Coated Quantum Dots and Adsorbed Proteins for Tracing Their Fate in Cell Cultures. ACS Nano 2019, 13, 4631-4639.

(36) Heuer-jungemann, A.; Feliu, N.; Bakaimi, I.; Hamaly, M.; Alkilany, A.; Chakraborty, I.; Masood, A.; Casula, M. F.; Kostopoulou, A.; Oh, E.; et al. The Role of Ligands in the Chemical Synthesis and Applications of Inorganic Nanoparticles. Chem. Rev. 2019, 119, 4819-4880.

(37) Shahabi, S.; Döscher, S.; Bollhorst, T.; Treccani, L.; Maas, M.; Dringen, R.; Rezwan, K. Enhancing Cellular Uptake and Doxorubicin Delivery of Mesoporous Silica Nanoparticles via Surface Functionalization: Effects of Serum. ACS Appl. Mater. Interfaces 2015, 7, 2688026891.

(38) Luo, Z.; Hu, Y.; Xin, R.; Zhang, B.; Li, J.; Ding, X.; Hou, Y.; Yang, L.; Cai, K. Surface Functionalized Mesoporous Silica Nanoparticles with Natural Proteins for Reduced Immunotoxicity. J. Biomed. Mater. Res. A 2013, 102, 3781-3794.
(39) Mandal, T.; Beck, M.; Kirsten, N.; Lindén, M.; Buske, C. Targeting Murine Leukemic Stem Cells by Antibody Functionalized Mesoporous Silica Nanoparticles. Sci. Rep. 2018, 8, No. 989.

(40) Bertrand, N.; Wu, J.; Xu, X.; Kamaly, N.; Farokhzad, O. C. Cancer Nanotechnology: The Impact of Passive and Active Targeting in the Era of Modern Cancer Biology. Adv. Drug Delivery Rev. 2014, $66,2-25$.

(41) Sun, T.; Zhang, Y. S.; Pang, B.; Hyun, D. C.; Yang, M.; Xia, Y. Engineered Nanoparticles for Drug Delivery in Cancer Therapy. Angew. Chem., Int. Ed. 2014, 53, 12320-12364.

(42) Xian, Y.; Xian, Y.; Zhou, L.; Wu, F.; Ling, Y.; Jin, L. Encapsulation Hemoglobin in Ordered Mesoporous Silicas: Influence Factors for Immobilization and Bioelectrochemistry. Electrochem. Commun. 2007, 9, 142-148.

(43) Baumann, B.; Wittig, R.; Lindén, M. Mesoporous Silica Nanoparticles in Injectable Hydrogels: Factors Influencing Cellular Uptake and Viability. Nanoscale 2017, 9, 12379-12390.

(44) Huang, X.; El-Sayed, I. H.; Qian, W.; El-Sayed, M. A. Cancer Cell Imaging and Photothermal Therapy in the near-Infrared Region by Using Gold Nanorods. J. Am. Chem. Soc. 2006, 128, 2115-2120.

(45) Xie, J.; Lee, S.; Chen, X. Nanoparticle-Based Theranostic Agents. Adv. Drug Delivery Rev. 2010, 62, 1064-1079.

(46) Chanana, M.; Gil, P. R.; Correa-duarte, M. A.; Liz-Marzan, L. M.; Parak, W. J. Physicochemical Properties of Protein-Coated Gold Nanoparticles in Biological Fluids and Cells before and after Proteolytic Digestion. Angew. Chem., Int. Ed. 2013, 52, 4179-4183.

(47) Wang, X.; Tan, L.-L.; Li, X.; Song, N.; Li, Z.; Hu, J.-N.; Cheng, Y.-M.; Wang, Y.; Yang, Y.-W. Smart Mesoporous Silica Nanoparticles Gated by Pillararene-Modified Gold Nanoparticles for on-Demand Cargo Release. Chem. Commun. 2016, 52, 13775-13778.

(48) Zhan, Q.; Qian, J.; Li, X.; He, S. A Study of Mesoporous SilicaEncapsulated Gold Nanorods as Enhanced Light Scattering Probes for Cancer Cell Imaging. Nanotechnology 2010, 21, No. 055704.

(49) Li, L.; Wang, H. Enzyme-Coated Mesoporous Silica Nanoparticles as Efficient Antibacterial Agents In Vivo. Adv. Healthcare Mater. 2013, 2, 1351-1360.

(50) Lee, W.; Park, E. J.; Kwak, S.; Kim, Y.; Na, D. H.; Bae, J. S. PEGylated Lysozymes with Anti-Septic Effects in Human Endothelial Cells and in Mice. Biochem. Biophys. Res. Commun. 2015, 459, 662667.

(51) Koutsopoulos, S.; Unsworth, L. D.; Nagai, Y.; Zhang, S. Controlled Release of Functional Proteins through Designer SelfAssembling Peptide Nanofiber Hydrogel Scaffold. Proc. Natl. Acad. Sci. U.S.A. 2009, 106, 4623-4628.

(52) Rabbani, G.; Ahmad, E.; Khan, M. V.; Ashraf, M. T.; Bhat, R.; Khan, R. H. Impact of Structural Stability of Cold Adapted Candida Antarctica Lipase B (CaLB): In Relation to $\mathrm{pH}$, Chemical and Thermal Denaturation. RSC Adv. 2015, 5, 20115-20131.

(53) Piludu, M.; Medda, L.; Monduzzi, M.; Salis, A. Gold Nanoparticles: A Powerful Tool to Visualize Proteins on Ordered Mesoporous Silica and for the Realization of Theranostic Nanobioconjugates. Int. J. Mol. Sci. 2018, 19, 1991.

(54) Perro, A.; Meunier, F.; Schmitt, V.; Ravaine, S. Production of Large Quantities of "Janus" nanoparticles Using Wax-in-Water Emulsions. Colloids Surf., A 2009, 332, 57-62.

(55) Phonthammachai, N.; Kah, J. C. Y.; Jun, G.; Sheppard, C. J. R.; Olivo, M. C.; Mhaisalkar, S. G.; White, T. J. Synthesis of Contiguous Silica - Gold Core - Shell Structures: Critical Parameters and Processes. Langmuir 2008, 24, 5109-5112.

(56) Jankiewicz, B. J.; Jamiola, D.; Choma, J.; Jaroniec, M. Silica Metal Core - Shell Nanostructures. Adv. Colloid Interface Sci. 2012, $170,28-47$.

(57) Choma, J.; Dziura, A.; Jamioła, D.; Nyga, P.; Jaroniec, M. Physicochemical and Engineering Aspects Preparation and Properties of Silica - Gold Core - Shell Particles. Colloids Surf., A 2011, 373, $167-171$.

(58) Westcott, S. L.; Oldenburg, S. J.; Lee, T. R.; Halas, N. J. Formation and Adsorption of Clusters of Gold Nanoparticles onto 
Functionalized Silica Nanoparticle Surfaces. Langmuir 1998, 14, $5396-5401$.

(59) Brewer, S. H.; Glomm, W. R.; Johnson, M. C.; Knag, M. K.; Franzen, S. Probing BSA Binding to Citrate-Coated Gold Nanoparticles and Surfaces. Langmuir 2005, 21, 9303-9307.

(60) Iosin, M.; Canpean, V.; Astilean, S. Spectroscopic Studies on $\mathrm{pH}-$ and Thermally Induced Conformational Changes of Bovine Serum Albumin Adsorbed onto Gold Nanoparticles. J. Photochem. Photobiol., A 2011, 217, 395-401.

(61) Winuprasith, T.; Suphantharika, M.; McClements, D. J.; He, L. Spectroscopic Studies of Conformational Changes of $\beta$-Lactoglobulin Adsorbed on Gold Nanoparticle Surfaces. J. Colloid Interface Sci. 2014, 416, 184-189.

(62) Vaishanav, S. K.; Chandraker, K.; Korram, J.; Nagwanshi, R.; Ghosh, K. K.; Satnami, M. L. Protein Nanoparticle Interaction: A Spectrophotometric Approach for Adsorption Kinetics and Binding Studies. J. Mol. Struct. 2016, 1117, 300-310.

(63) Cárdenas, B.; Sánchez-Obrero, G.; Madueño, R.; Sevilla, J. M.; Blázquez, M.; Pineda, T. Influence of the Global Charge of the Protein on the Stability of Lysozyme - AuNP Bioconjugates. J. Phys. Chem. C 2014, 118, 22274-22283.

(64) Du, J.; Xia, Z. Interactions of Gold Nanoparticles and Lysozyme by Fluorescence Quenching Method. Anal. Lett. 2012, $45,2236-2245$.

(65) Majorek, K. A.; Porebski, P. J.; Dayal, A.; Zimmerman, M. D.; Jablonska, K.; Stewart, A. J.; Chruszcz, M.; Minor, W. Structural and Immunologic Characterization of Bovine, Horse, and Rabbit Serum Albumins. Mol. Immunol. 2012, 52, 174-182.

(66) Diamond, R. Real-Space Refinement of the Structure of Hen Egg-White Lysozyme. J. Mol. Biol. 1974, 82, 371-391.

(67) Iosin, M.; Toderas, F.; Baldeck, P. L.; Astilean, S. Study of Protein-Gold Nanoparticle Conjugates by Fluorescence and SurfaceEnhanced Raman Scattering. J. Mol. Struct. 2009, 924-926, 196-200.

(68) Zhang, D.; Neumann, O.; Wang, H.; Yuwono, V. M.; Barhoumi, A.; Perham, M.; Hartgerink, J. D.; Wittung-Stafshede, P.; Halas, N. J. Gold Nanoparticles Can Induce the Formation of ProteinBased Aggregates at Physiological pH. Nano Lett. 2009, 9, 666-671.

(69) Nairi, V.; Magnolia, S.; Piludu, M.; Nieddu, M.; Caria, C. A.; Sogos, V.; Vallet-Regì, M.; Monduzzi, M.; Salis, A. Mesoporous Silica Nanoparticles Functionalized with Hyaluronic Acid. Effect of the Biopolymer Chain Length on Cell Internalization. Colloids Surf., B 2018, 168, 50-59.

(70) Sing, K. The Use of Nitrogen Adsorption for the Characterisation of Porous Materials. Colloids Surf., A 2001, 187-188, 3-9. 